\title{
Leptin Deficiency and Its Effects on Tibial and Vertebral Bone Mechanical Properties in Mature Genetically Lean and Obese JCR:LA-Corpulent Rats
}

\author{
Raylene A. Reimer, ${ }^{1,2}$ Jeremy M. LaMothe, ${ }^{1,2}$ and Ronald F. Zernicke ${ }^{1,2,3}$ \\ ${ }^{1}$ Faculties of Kinesiology and Medicine, University of Calgary, 2500 University Drive NW, Calgary, AB, Canada T2N 1N4 \\ ${ }^{2}$ Department of Biochemistry and Molecular Biology, Faculty of Medicine, University of Calgary, Calgary, AB, Canada T2N 4N1 \\ ${ }^{3}$ Departments of Orthopaedic Surgery and Biomedical Engineering and School of Kinesiology, University of Michigan, \\ Ann Arbor, MI 48109, USA
}

Correspondence should be addressed to Raylene A. Reimer, reimer@ucalgary.ca

Received 4 February 2012; Revised 18 June 2012; Accepted 18 June 2012

Academic Editor: Yvon Chagnon

Copyright ( $) 2012$ Raylene A. Reimer et al. This is an open access article distributed under the Creative Commons Attribution License, which permits unrestricted use, distribution, and reproduction in any medium, provided the original work is properly cited.

Leptin signaling deficient rodents have emerged as models of obesity/insulin resistance syndrome. Altered leptin signaling, however, can affect axial and appendicular bone geometrical properties differently, and, thus, we hypothesized that leptindeficiency would differentially influence mechanical properties of vertebrae and tibiae compared to lean rats. Mature (9 mo) leptin receptor deficient obese $(c p / c p ; n=8)$ and lean $(+/$ ?; $n=7)$ male JCR:LA-corpulent rats were used to test that hypothesis. Tibiae and the sixth lumbar vertebrae $\left(L_{6}\right)$ were scanned with micro-CT and were broken in three point-bending (tibiae) or axial loading $\left(L_{6}\right)$. Supporting the hypothesis, vertebrae and tibiae were differentially affected by leptin signaling deficiency. Tibiae, but not vertebrae, were significantly shorter in obese rats and achieved a significantly greater load $(>18 \%)$, displacement $(>15 \%)$, and stress $(>18 \%)$ at the proportional limit, relative to the lean rats. Conversely, $L_{6}$ in obese rats had significantly reduced displacement $(>25 \%)$ and strain $(>32 \%)$ at proportional limit, relative to the lean rats. Those combined results suggest that the etiology and duration of obesity may be important determinants of bone mechanical properties, and axial and appendicular bones may be affected differently.

\section{Introduction}

Obesity and its attendant complications threaten the sustainability of many health care systems worldwide [1]. While an increased risk of developing type 2 diabetes, cardiovascular disease, and certain cancers is a well-recognized corollary of obesity, recent evidence points to the risk of perturbations in bone health as well [2-4]. Several mechanisms have been proposed to explain the interrelation between obesity and bone metabolism, including increased proinflammatory cytokines and excessive leptin secretion [2].

The discovery of leptin as an adipose-derived hormone involved in energy balance provided key insights into the molecular pathogenesis of obesity $[5,6]$. Leptin is a $14 \mathrm{kD}$ protein secreted by white adipose cells [7] and is strongly correlated with body fat mass [8]. While leptin plays an important role in appetite regulation and energy metabolism, it is also a powerful inhibitor of bone mass accrual [9].

Animals lacking functional leptin signaling manifest severe obesity and its related diseases. The JCR:LA-corpulent rat is such a model. JCR:LA-corpulent rats have a mutation in the leptin receptor $(c p)$ gene, leading to a complete absence of functional leptin receptors [10]. Rats homozygous for that mutation $(c p / c p)$ are highly obese and are used as an animal model for obesity/insulin resistance syndrome (see [11] for review). Rats heterozygous for the cp mutation $(+/ c p)$ and homozygous normal rats $(+/+)$ are phenotypically indistinguishable and can collectively be used as lean controls $(+/$ ?) [12]. 
Leptin has a plethora of influences on hormonal and trophic factors, all of which can influence bone metabolism. Exogenous administration of leptin can act via the central nervous system to inhibit bone formation $[13,14]$ or peripherally to enhance bone formation [15], although more recent studies with lower doses of intracerebroventricular leptin administration show enhanced bone formation with increased osteoprotegerin (OPG), osteocalcin, and receptor activator of nuclear factor $\kappa \beta$ ligand (RANKL) levels [16]. Impaired leptin signaling influenced bones in a site-specific manner. Leptin-deficient mice had suppressed femoral bone mineral density (BMD) and enhanced lumbar BMD, relative to lean mice [17]. Those changes were reported for bone geometry and not specific to the bone material irrespective of geometry. Because JCR:LA-corpulent rats manifest an obesity/insulin resistant phenotype, and diabetes mellitus can cause a degeneration in bone material properties [18, 19], potentially, the mechanical properties of obese/insulin resistant rat bones would differ from those of controls. Thus, we hypothesized that leptin receptor deficiency would differentially influence mechanical properties of vertebrae and tibiae of JCR:LA-corpulent rats compared to lean rats.

\section{Materials and Methods}

2.1. Animals. Mature ( 9 months) male obese $(c p / c p ; n=8)$ and lean $(+/$; $n=7)$ JCR:LA-corpulent rats were obtained from Dr. J. Russell's colony (University of Alberta). The JCR:LA-corpulent rats are patently obese at 3 weeks (wk) of age, and moderate hyperinsulinaemia can be observed already at 4 wk [20]. Rats were housed in a temperatureand humidity-controlled room with a reverse $12 \mathrm{~h}$ light/dark cycle (19:00 to 07:00). Rats were housed 2 per cage at the University of Calgary $1 \mathrm{wk}$ prior to sacrifice. Standard rat chow (5P14 ModRod EQ, Richmond, IN, USA) and water were provided ad libitum for both lean and obese rats. All procedures were ethically approved by the University of Calgary Animal Welfare Committee.

2.2. Tibial and $L_{6}$ Preparation. Immediately after euthanization (halothane anaesthesia followed by cervical dislocation) tibiae and the sixth lumbar vertebrae $\left(L_{6}\right)$ were dissected and cleaned of adherent muscular and connective tissues. To isolate the vertebral centrum, the neural spine, transverse processes, and zygapophyses were removed from each vertebra with a diamond wafer saw (Buehler Isomet, Lake Bluff, IL, USA) [21]. To ensure parallel caudal and rostral vertebral surfaces (for biomechanical testing), those surfaces were cleaned of intervertebral discs and a wafer was cut from the caudal surface parallel to the rostral surface bringing the total length of the tested centrum to $80 \%$ of the centrum length in its entirety [21]. Bones were individually wrapped in saline-soaked gauze (50 $\mathrm{mM}$ potassium phosphate buffer solution, $\mathrm{pH}=7.4$ ) and sealed hermetically in plastic bags that were frozen $\left(-30^{\circ} \mathrm{C}\right)$ for less than 1 month until biomechanical testing. Freezing and thawing has been shown to not adversely affect bone mechanical properties [22].
2.3. Tibial Bone Geometry. Tibiae were thawed in $22^{\circ} \mathrm{C}$ buffer ( $50 \mathrm{mM}$ potassium phosphate buffer solution, $\mathrm{pH}=7.4$ ) for 1 hour and subjected to micro-CT scanning (Skyscan 1073, Aartselaar, Belgium) at a magnification of $14 \mathrm{x}$ (resolution of $20 \mu \mathrm{m}$ ). Bitmap images generated from scanning that represented the tibial longitudinal midpoints (one image per tibia) were used as input to custom software (Matlab, Natick, MA, USA) that thresholded images and calculated geometric parameters including total cross-sectional area, distances from centroid to the lateral surface of the cross-section, and cross-sectional moment of inertia. After scanning, tibiae were rewrapped in saline soaked gauze, hermetically sealed, and frozen $\left(-30^{\circ} \mathrm{C}\right)$ until biomechanical testing.

2.4. Tibial Biomechanical Testing. On the day of testing, tibiae were thawed in $22^{\circ} \mathrm{C}$ buffer $(50 \mathrm{mM}$ potassium phosphate buffer solution, $\mathrm{pH}=7.4$ ) for $1 \mathrm{hr}$. When thawed, tibial length was measured using callipers (Model 599-578-1, Brown and Sharpe, Irvine, CA, USA) and tibiae were placed on a round surfaced $13.3 \mathrm{~mm}$ loading span. The cross-sectional shape of tibiae (triangular) permitted stable and repeatable placement of the diaphyseal shaft on the loading span. The round-surfaced cross-head probe of a servocontrolled electromechanical testing system (Model 1122, Instron Corp., Canton, MA, USA) contacted the medial tibial surface at its longitudinal midpoint and applied a preload of $1 \mathrm{~N}$; the medial surface was in compression and the lateral surface was in tension. Load was applied at $25.4 \mathrm{~mm} / \mathrm{min}$ until failure, and testing order was stratified based on group to eliminate potential testingorder effects. Load deformation curves were acquired (RC Computerscope A/D Board, RC Electronics, Santa Barbara, CA, USA) at $200 \mathrm{~Hz}$. From the load-deformation curves, load and displacement and energy at proportional limit, maximal load, and flexural rigidity (structural properties) were determined. Structural properties were used in conjunction with geometrical properties ( $\mu \mathrm{CT}$ scanning) to calculate material properties, including stress and strain at proportional limit, maximal load, and modulus of elasticity.

2.5. $L_{6}$ Bone Geometry. Vertebrae were thawed in $22^{\circ} \mathrm{C}$ buffer ( $50 \mathrm{mM}$ potassium phosphate buffer solution, $\mathrm{pH}=7.4$ ) for $1 \mathrm{hr}$ and subjected to micro-CT scanning (Skyscan 1073, Aartselaar, Belgium) at a magnification of 30x (resolution of $13 \mu \mathrm{m})$. In the sagittal plane, centra had an hourglass appearance. In axial biomechanical testing, the narrowest region of the centrum (i.e., centre of the hourglass) was subjected to the greatest stress, and, thus, centrum transverse sections corresponding to the narrowest region of the vertebral centra were used for geometrical determination. Bitmap images generated from scanning of that region (one image per centrum) were used as input to customized software (Matlab, MathWorks, Natick, MA, USA) that determined total cross sectional area, trabecular area, and cortical bone area (Scion Image, Frederick, MD, USA). Vertebral height was measured with callipers (Model 599-578-1, Brown and Sharpe, Irvine, CA, USA). After scanning, $L_{6}$ were rewrapped in saline 
TABLE 1: Tibial geometrical properties.

\begin{tabular}{lccc}
\hline & Lean & Obese & $n$ \\
\hline Tibial length $(\mathrm{mm})$ & $42.01 \pm 1.02^{*}$ & $40.10 \pm 0.67$ & \\
Tibial mass $(\mathrm{g})$ & $1.37 \pm 0.19$ & $1.27 \pm 0.09$ & 31 \\
Cross-sectional area $\left(\mathrm{mm}^{2}\right)$ & $5.42 \pm 0.46$ & $5.53 \pm 0.28$ & 178 \\
Cross-sectional moment of & $3.40 \pm 0.56$ & $3.44 \pm 0.44$ & 2453 \\
inertia $I_{x x}\left(\mathrm{~mm}^{4}\right)$ & $389.5 \pm 32.7^{*}$ & $807.5 \pm 53.0$ & \\
Body mass $(\mathrm{g})$ & &
\end{tabular}

Values are means $\pm \mathrm{SD} .{ }^{*}$ denotes statistically significant $(P \leq 0.05) . n$ denotes the sample size per group needed for the recorded differences to become statistically significant based on a power of 0.8 .

soaked gauze hermetically sealed, and frozen $\left(-30^{\circ} \mathrm{C}\right)$ until biomechanical testing.

2.6. $L_{6}$ Biomechanical Testing. On the day of testing, $L_{6}$ vertebrae were thawed in $22^{\circ} \mathrm{C}$ buffer $(50 \mathrm{mM}$ potassium phosphate buffer solution, $\mathrm{pH}=7.4$ ) for at least $1 \mathrm{hr}$. The caudal surface of the centrum was placed on a stainless steel plate thinly coated with mineral oil to approximate unconstrained compression. The flat-surfaced cross head of a servocontrolled electromechanical testing system (Model 1122, Instron Corp., Canton, MA, USA) was lubricated and contacted the rostral surface of the centrum with a preload of $5 \mathrm{~N}$. The centrum was cycled from 5-10 N 20 times at $0.001 \% / \mathrm{s}$ to eliminate viscoelastic creep of trabecular bone [23]. Cycling was stopped at a preload of $10 \mathrm{~N}$, and samples were subsequently compressed at $127 \mathrm{~mm} / \mathrm{min}$. Testing was stratified based on group to prevent a testingorder effect. Load deformation curves were acquired (RC Computerscope A/D Board) at $200 \mathrm{~Hz}$ and were used to determine load and displacement and energy to proportional limit, maximal load, and stiffness (structural properties). Geometrical data (micro-CT scanning) were used with the structural properties to determine stress and strain at the proportional limit and at maximal load and the apparent elastic modulus [24].

2.7. Ash Analyses. Crushed $L_{6}$ centra and a $2 \mathrm{~mm}$ section of the tibial diaphysis immediately distal to the middiaphyseal fracture site were dehydrated in $100 \%$ ethanol for $5 \mathrm{~d}$, defatted in acetone for $5 \mathrm{~d}$, and dried at $100^{\circ} \mathrm{C}$ (Thermolyne F62700, Dubuque, IA, USA) for $48 \mathrm{hr}$ in a ceramic crucible. Dried bone samples were weighed (Mettler $\mathrm{AE} 163$, Anaheim, CA, USA; $\pm 10 \mu \mathrm{g}$ ) to determine dry bone mass. After weighing, samples were incinerated at $600^{\circ} \mathrm{C}$ for $5 \mathrm{~d}$. The ash was weighed, and mineral ash fraction was calculated as (ash mass) $/$ (dry mass) $\times 100 \%$.

2.8. Plasma Leptin. Following an overnight fast, blood was collected from each rat into a chilled tube containing $1 \mathrm{mg} / \mathrm{mL}$ of EDTA, aprotinin (500 kallikrein inhibitor units/mL; Sigma Chemical Co.), and diprotin-A (0.1 mM). The blood was centrifuged at $1600 \times \mathrm{g}$ for $15 \mathrm{~min}$ at $4^{\circ} \mathrm{C}$ and plasma aliquots stored at $-80^{\circ} \mathrm{C}$. A Rat Endocrine

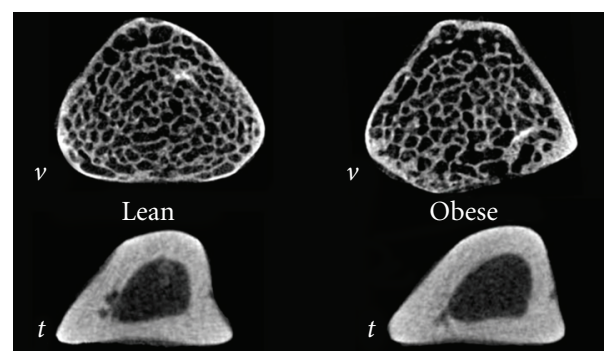

Figure 1: Exemplar $L_{6}(v)$ and tibial $(t)$ transverse cross-sectional micro-CT images for lean and genetically obese rats.

LINCOplex kit was used to quantify leptin (Linco Research Inc., Millipore, Billerica, MA, USA) with a sensitivity of $6.2 \mathrm{pM}$.

2.9. Statistics. Mann-Whitney comparisons determined where intergroup significant differences were present (SPSS, Chicago, IL, USA). Where no significant differences were present, the sample size required per group for the values to reach significance was calculated based on a significance level of 0.05 and a power of 0.8 . A significance level of $P \leq 0.05$ was used for all statistical tests. Reported values are means \pm SD.

\section{Results}

3.1. Tibiae. Obese rats had significantly greater body mass $(>107 \%)$, and their tibiae were significantly shorter relative to lean rats (Table 1). Tibial cross-sectional structural properties, however, were not adversely affected in the obese rats (Figure 1, Table 2). There were minimal significant differences between obese and lean rats, and those differences were confined to load and displacement at proportional limit. Load and displacement at proportional limit were significantly greater in obese rats. Similar to structural properties, there were minimal significant differences between obese and lean tibial material properties (Table 3). Obese tibiae had a significantly greater stress at proportional limit, relative to lean tibiae. There were no significant differences in structural or material properties at maximal load.

3.2. Vertebrae. There were no significant differences in vertebral geometrical properties between obese and lean $L_{6}$ (Table 4). Similarly, there were minimal significant differences in vertebral structural properties (Table 5). Conversely to the tibiae, displacement at proportional limit was significantly less in the obese $L_{6}$, relative to lean $L_{6}$. As with the structural properties, there were minimal significant differences in the majority of $L_{6}$ material properties (Table 6). The only difference that was significant was that strain at proportional limit was greater in lean rats. There were no significant differences in structural or material properties at maximal load. 
TABLE 2: Tibial structural properties.

\begin{tabular}{|c|c|c|c|}
\hline & Lean & Obese & $n$ \\
\hline Flexural rigidity $\left(\mathrm{N} \cdot \mathrm{mm}^{2} \cdot 10^{3}\right)$ & $5.37 \pm 0.81$ & $5.40 \pm 0.34$ & 5868 \\
\hline Load at proportional limit $(\mathrm{N})$ & $25.49 \pm 2.94^{*}$ & $30.22 \pm 3.41$ & \\
\hline Displacement at proportional limit $(\mathrm{mm})$ & $0.26 \pm 0.04^{*}$ & $0.30 \pm 0.02$ & \\
\hline Maximal load (N) & $36.13 \pm 4.48$ & $39.34 \pm 3.67$ & 26 \\
\hline Displacement at maximal load (mm) & $0.61 \pm 0.10$ & $0.60 \pm 0.08$ & 1272 \\
\hline Energy to proportional limit $\left(\mathrm{N} \cdot \mathrm{mm} \cdot 10^{3}\right)$ & $4.12 \pm 0.76$ & $5.06 \pm 0.89$ & 49 \\
\hline Energy to maximal load $\left(\mathrm{N} \cdot \mathrm{mm} \cdot 10^{4}\right)$ & $1.78 \pm 0.45$ & $1.56 \pm 0.78$ & 123 \\
\hline
\end{tabular}

Values are means $\pm \mathrm{SD}$. ${ }^{*}$ denotes statistically significant $(P \leq 0.05) . n$ denotes the sample size per group needed for the recorded differences to become statistically significant based on a power of 0.8 .

TABLE 3: Tibial material properties.

\begin{tabular}{lccc}
\hline & Lean & Obese & $n$ \\
\hline Modulus of elasticity $(\mathrm{GPa})$ & $1.60 \pm 0.24$ & $1.59 \pm 0.25$ & \\
Stress at proportional limit $(\mathrm{MPa})$ & $27.90 \pm 2.81^{*}$ & $33.12 \pm 6.14$ & \\
Strain at proportional limit $(\%)$ & $1.97 \pm 0.36$ & $2.29 \pm 0.09$ & 8 \\
Stress at maximal load $(\mathrm{MPa})$ & $39.53 \pm 4.45$ & $42.96 \pm 6.16$ & 38 \\
Strain at maximal load $(\%)$ & $4.60 \pm 0.98$ & $4.58 \pm 0.76$ & 29705 \\
Mineral ash fraction $(\%)$ & $71.94 \pm 0.28$ & $72.53 \pm 0.43$ & 9 \\
\hline
\end{tabular}

Values are means $\pm \mathrm{SD}$. ${ }^{*}$ denotes statistically significant $(P \leq 0.05) . n$ denotes the sample size per group needed for the recorded differences to become statistically significant based on a power of 0.8 .

TABLE 4: $L_{6}$ geometrical properties.

\begin{tabular}{lccc}
\hline & Lean & Obese & $n$ \\
\hline Vertebral height $(\mathrm{mm})$ & $7.46 \pm 0.32$ & $7.57 \pm 0.51$ & 224 \\
Total area $\left(\mathrm{mm}^{2}\right)$ & $12.55 \pm 2.10$ & $14.06 \pm 1.43$ & 22 \\
Trabecular area $\left(\mathrm{mm}^{2}\right)$ & $7.59 \pm 2.08$ & $8.81 \pm 1.17$ & 28 \\
Cortical area $\left(\mathrm{mm}^{2}\right)$ & $4.96 \pm 0.83$ & $5.24 \pm 1.00$ & 168 \\
\hline
\end{tabular}

Values are means \pm SD. $n$ denotes the sample size per group needed for the recorded differences to become statistically significant.

3.3. Plasma Leptin. Plasma leptin was $193.7 \pm 18.8 \mathrm{pM}$ in lean rats and $728.6 \pm 17.1 \mathrm{pM}$ in obese rats which was significantly different $(P=0.001)$.

\section{Discussion}

Obese $c p / c p$ JCR:LA-corpulent rats are leptin receptor deficient and have been used as a model of genetic-related obesity with accompanying hyperleptinemia and hyperinsulinemia [25]. We show that plasma leptin was approximately 4 -fold higher in the obese versus lean rats, a pattern that is similar to the 12 -fold higher plasma insulin we have previously shown in these rats [26]. The current study assessed the mechanical properties of the tibiae and vertebrae of those rats and found that tibiae and vertebrae were differentially affected by leptin receptor deficiency. Tibiae were significantly shorter in obese rats and had significantly greater loads, displacements, and stresses at the proportional limit, relative to the lean rats. Conversely, vertebrae in obese rats had significantly smaller displacements and strains at proportional limit, relative to the lean rats. Changes in tibial and vertebral mechanical properties were minimal in that there were no significant differences when mechanical properties were assessed at maximal load.

Detecting minimal changes between obese and lean rats was unanticipated given that leptin deficiency is associated with a myriad of factors favoring bone loss including hypogonadism, hypercortisolism, reduced trophic factors, and reduced activity levels [13, 17, 27]. One potential explanation for the minimal change in bone structural and material properties is that leptin deficiency causes significant obesity, and that an increase in body mass could subject bones to greater mechanical forces, which may be protective against bone loss [28]. It could also be suggested that if the obese rats attain maximal body weight earlier, the continued growth trajectory of the lean rats could minimize differences between the groups. Our previous work with this model in fact shows the opposite and it is the obese rats that continue to accrue mass at a greater magnitude than the lean rats [29]. Additionally, a lack of cerebral leptin signaling may enhance osteoblast activities thereby augmenting bone formation [13]. The minimal changes observed in mechanical properties could suggest that the overall influence of leptin deficiency on bone may be a dynamic balance between the bone-formation favoring and the bone loss-promoting actions of leptin.

The current study was consistent with previous studies in that the leptin-deficient rodents were significantly heavier $[11,25]$ and their appendicular bones were significantly shorter with a lower bone mineral density $[30,31]$ than lean rodents. Those shortened bones may have resulted from elevated 1,25- $(\mathrm{OH})_{2} \mathrm{D}_{3}$ levels [30], suppressed trophic factors (such as IGF-1, GH, or TGF $\beta-1$ ) $[17,32]$, or decreased 
TABLE 5: $L_{6}$ structural properties.

\begin{tabular}{|c|c|c|c|}
\hline & Lean & Obese & $n$ \\
\hline Stiffness $\left(\mathrm{N} \cdot \mathrm{mm}^{-1}\right)$ & $244.01 \pm 19.80$ & $248.52 \pm 34.23$ & 564 \\
\hline Load at proportional limit $(\mathrm{N})$ & $120.84 \pm 19.56$ & $101.34 \pm 20.34$ & 17 \\
\hline Displacement at proportional limit $(\mathrm{mm})$ & $0.75 \pm 0.15^{*}$ & $0.56 \pm 0.09$ & \\
\hline Maximal load $(\mathrm{N})$ & $137.88 \pm 17.90$ & $132.58 \pm 20.16$ & 203 \\
\hline Displacement at maximal load (mm) & $1.07 \pm 0.32$ & $1.30 \pm 0.46$ & 46 \\
\hline Energy to proportional limit $\left(\mathrm{N} \cdot \mathrm{mm} \cdot 10^{3}\right)$ & $8.69 \pm 2.82$ & $5.91 \pm 1.95$ & 12 \\
\hline Energy to maximal load $\left(\mathrm{N} \cdot \mathrm{mm} \cdot 10^{4}\right)$ & $1.87 \pm 0.71$ & $2.64 \pm 1.31$ & 27 \\
\hline
\end{tabular}

Values are means $\pm \mathrm{SD}$. ${ }^{*}$ denotes statistically significant $(P \leq 0.05) . n$ denotes the sample size per group needed for the recorded differences to become statistically significant based on a power of 0.8 .

TABLE 6: $L_{6}$ material properties.

\begin{tabular}{lccc}
\hline & Lean & Obese & $n$ \\
\hline Apparent elastic modulus (MPa) & $115.83 \pm 26.17$ & $107.63 \pm 8.65$ & 71 \\
Stress at proportional limit (MPa) & $9.42 \pm 2.37$ & $7.25 \pm 1.53$ & 13 \\
Strain at proportional limit (\%) & $13.47 \pm 2.54^{*}$ & $9.07 \pm 2.09$ & \\
Stress at maximal load (MPa) & $10.68 \pm 2.11$ & $9.47 \pm 1.40$ & 34 \\
Strain at maximal load (\%) & $19.01 \pm 5.04$ & $21.00 \pm 7.94$ & 167 \\
Mineral ash fraction $(\%)$ & $63.43 \pm 0.85$ & $63.44 \pm 1.14$ & 155412 \\
\hline
\end{tabular}

Values are means $\pm \mathrm{SD}$. ${ }^{*}$ denotes statistically significant $(P \leq 0.05) . n$ denotes the sample size per group needed for the recorded differences to become statistically significant based on a power of 0.8 .

muscle masses [17]. Prisby and colleagues [31] showed that longitudinal growth was compromised in tibiae and femora in the prediabetes state ( $7 \mathrm{wk}$ of age) in Zucker diabetic fatty (ZDF) rats, which similar to the JCR:LA cp rats, are leptin receptor deficient. The impaired growth was evident prior to the development of overt hyperglycemia, thereby suggesting that factors other than those related to excess glucose were involved. Hamann and coworkers [33] showed that suppressed osteoblastogenesis could explain the low bone mass in ZDF rats with well-established insulin-resistant type 2 diabetes.

In contrast to shortened appendicular bones, vertebral height and bone mineral density were greater in leptindeficient $(o b / o b)$ mice, relative to the lean mice [17]. The current results also revealed different trends in vertebral and tibial properties. Tibiae in the obese rats underwent greater displacement at the proportional limit and carried a greater load at the proportional limit. The corresponding material property, stress at proportional limit, was greater in the obese rats suggesting that changes in material properties contributed to the observed changes in structural properties. Vertebrae in the obese rats underwent significantly less displacement to the proportional limit, relative to lean controls. The corresponding material property, strain at proportional limit, was also significantly less in the obese vertebrae suggesting again that material properties contributed to changes in structural properties.

It remains unclear why vertebrae and tibiae were differentially affected. This site difference, however, has been suggested by some [31] to perhaps account for controversial reports of protective or detrimental effects of type 2 diabetes on skeletal properties in the human literature. One factor could have related to tibial and vertebral growth plates responding differently to leptin deficiency [17]; in the current study tibiae were significantly shorter, and the vertebrae were unaltered, relative to the controls. Alternatively, different responses may have arisen from perturbations secondary to leptin-deficiency, such as alterations in muscle mass [17], different mechanical environments of the tibia and spine, or alterations in the marrow environment [17].

The current study, in conjunction with diet-induced obesity studies [34-36], suggested that the mechanism of obesity was an important factor in how obesity affected bone properties. While the current study showed that decrements in bone mechanical properties in the leptin receptor deficient obese rats (genetic-related obesity) were minimal and limited to the proportional limit, Zernicke and colleagues [35] showed that decrements in bone mechanical properties for high-fat sucrose (HFS) fed obese rats (diet-related obesity) were substantial at proportional limit and maximal load (30\% reduction in $L_{6}$ maximal stress). Moreover, Lorincz and coworkers [36] showed that structural and morphological properties of tibiae were adversely affected in mice fed an HFS diet. Lower cortical thickness, cross-sectional area, and load at maximum were seen in HFS versus control mice [36]. It was suggested that upregulation of RANKL and cyclooxygenase-2 mRNA levels might reflect elevated osteoclast activity in response to the inflammatory state of the dietinduced obesity. Collectively, those dissimilar findings suggest that disparate effects exist between dietary factors that 
promote obesity and the array of adipokines (e.g., leptin) and other factors released from adipose tissue. Taken together, the data suggest that the etiology of obesity (i.e., genetic versus diet-related) is an important consideration when assessing the influence of obesity on bone mechanical properties.

\section{Conclusions}

Mechanical properties of obese and lean JCR:LA-corpulent rat tibiae and vertebrae were assessed. Changes in mechanical properties were minimal and limited to the proportional limit. Supporting the premise that leptin-deficiency affects tibiae and vertebrae differently, the mechanical properties of obese tibiae were enhanced while those of vertebrae were diminished, relative to the lean controls. The reported changes specific to leptin-deficiency-induced obesity were different than previously reported changes that occur with dietary induced obesity. Collectively, those data suggest the etiology of obesity may influence how obesity affects bone mechanical properties.

\section{Acknowledgments}

This work was funded in part by the Canadian Institutes of Health Research and the Natural Sciences and Engineering Research Council of Canada. The authors declare no conflict of interests.

\section{References}

[1] Y. C. Wang, K. McPherson, T. Marsh, S. L. Gortmaker, and M. Brown, "Health and economic burden of the projected obesity trends in the USA and the UK," The Lancet, vol. 378, no. 9793, pp. 815-825, 2011.

[2] J. J. Cao, "Effects of obesity on bone metabolism," Journal of Orthopaedic Surgery and Research, vol. 6, article 30, 2011.

[3] S. Migliaccio, E. A. Greco, R. Fornari, L. M. Donini, and A. Lenzi, "Is obesity in women protective against osteoporosis?" Diabetes, Metabolic Syndrome and Obesity, vol. 4, pp. 273-282, 2011.

[4] M. Holeckiand and A. Wiecek, "Relationship between body fat mass and bone metabolism," Polskie Archiwum Medycyny Wewnetrznej, vol. 120, no. 9, pp. 361-367, 2010.

[5] F. F. Chehab, J. Qiu, and S. Ogus, "The use of animal models to dissect the biology of leptin," Recent Progress in Hormone Research, vol. 59, pp. 245-266, 2004.

[6] Y. Zhang, R. Proenca, M. Maffei, M. Barone, L. Leopold, and J. M. Friedman, "Positional cloning of the mouse obese gene and its human homologue," Nature, vol. 372, no. 6505, pp. 425432, 1994

[7] S. Cinti, R. C. Frederich, M. C. Zingaretti, R. De Matteis, J. S. Flier, and B. B. Lowell, "Immunohistochemical localization of leptin and uncoupling protein in white and brown adipose tissue," Endocrinology, vol. 138, no. 2, pp. 797-804, 1997.

[8] M. Maffei, J. Halaas, E. Ravussin et al., "Leptin levels in human and rodent: measurement of plasma leptin and ob RNA in obese and weight-reduced subjects," Nature Medicine, vol. 1, no. 11, pp. 1155-1161, 1995.

[9] F. Elefteriou, S. Takeda, K. Ebihara et al., "Serum leptin level is a regulator of bone mass," Proceedings of the National Academy of Sciences of the United States of America, vol. 101, no. 9, pp. 3258-3263, 2004.

[10] S. Koletsky, "Pathologic findings and laboratory data in a new strain of obese hypertensive rats," American Journal of Pathology, vol. 80, no. 1, pp. 129-142, 1975.

[11] J. C. Russell, S. Graham, and M. Hameed, "Abnormal insulin and glucose metabolism in the JCR:LA-corpulent rat," Metabolism, vol. 43, no. 5, pp. 538-543, 1994.

[12] M. Richardson, A. M. Schmidt, S. E. Graham, B. Achen, M. DeReske, and J. C. Russell, "Vasculopathy and insulin resistance in the JCR:LA-cp rat," Atherosclerosis, vol. 138, no. 1, pp. 135-146, 1998.

[13] P. Ducy, M. Amling, S. Takeda et al., "Leptin inhibits bone formation through a hypothalamic relay: a central control of bone mass," Cell, vol. 100, no. 2, pp. 197-207, 2000.

[14] S. Takeda, F. Elefteriou, R. Levasseur et al., "Leptin regulates bone formation via the sympathetic nervous system," Cell, vol. 111, no. 3, pp. 305-317, 2002.

[15] C. M. Steppan, D. T. Crawford, K. L. Chidsey-Frink, H. Ke, and A. G. Swick, "Leptin is a potent stimulator of bone growth in ob/ob mice," Regulatory Peptides, vol. 92, no. 1-3, pp. 73-78, 2000.

[16] S. M. Bartell, S. Rayalam, S. Ambati et al., "Central (ICV) leptin injection increases bone formation, bone mineral density, muscle mass, serum IGF-1, and the expression of osteogenic genes in leptin-deficient ob/ob mice," Journal of Bone and Mineral Research, vol. 26, no. 8, pp. 1710-1720, 2011.

[17] M. W. Hamrick, C. Pennington, D. Newton, D. Xie, and C. Isales, "Leptin deficiency produces contrasting phenotypes in bones of the limb and spine," Bone, vol. 34, no. 3, pp. 376-383, 2004.

[18] J. C. H. Hou, R. F. Zernicke, and R. J. Barnard, "Experimental diabetes, insulin treatment, and femoral neck morphology and biomechanics in rats," Clinical Orthopaedics and Related Research, vol. 264, pp. 278-285, 1991.

[19] G. K. Reddy, L. Stehno-Bittel, S. Hamade, and C. S. Enwemeka, "The biomechanical integrity of bone in experimental diabetes," Diabetes Research and Clinical Practice, vol. 54, no. 1 , pp. 1-8, 2001.

[20] D. N. Brindley and J. C. Russell, "Animal models of insulin resistance and cardiovascular disease: some therapeutic approaches using the JCR:LA-cp rat," Diabetes, Obesity and Metabolism, vol. 4, no. 1, pp. 1-10, 2002.

[21] G. J. Salem, R. F. Zernicke, D. A. Martinez, and A. C. Vailas, "Adaptations of immature trabecular bone to moderate exercise: geometrical, biochemical, and biomechanical correlates," Bone, vol. 14, no. 4, pp. 647-654, 1993.

[22] R. R. Pelker, G. E. Friedlaender, T. C. Markham, M. M. Panjabi, and C. J. Moen, "Effects of freezing and freeze-drying on the biomechanical properties of rat bone," Journal of Orthopaedic Research, vol. 1, no. 4, pp. 405-411, 1984.

[23] F. Linde and I. Hvid, "The effect of constraint on the mechanical behaviour of trabecular bone specimens," Journal of Biomechanics, vol. 22, no. 5, pp. 485-490, 1989.

[24] G. J. Salem, R. F. Zernicke, D. A. Martinez, and A. C. Vailas, "Biomechanical and biochemical changes in lumbar vertebrae of rapidly growing rats," American Journal of Physiology, vol. 2561, no. 1, part 2, pp. R259-R263, 1989.

[25] R. A. Reimer and J. C. Russell, "Glucose tolerance, lipids, and GLP-1 secretion in JCR:LA-cp rats fed a high protein fiber diet," Obesity, vol. 16, no. 1, pp. 40-46, 2008.

[26] J. A. Parnell and R. A. Reimer, "Differential secretion of satiety hormones with progression of obesity in JCR:LA-corpulent rats," Obesity, vol. 16, no. 4, pp. 736-742, 2008. 
[27] P. Ruegsegger, T. C. Medici, and M. Anliker, "Corticosteroidinduced bone loss. A longitudinal study of alternate day therapy in patients with bronchial asthma using quantitative computed tomography," European Journal of Clinical Pharmacology, vol. 25, no. 5, pp. 615-620, 1983.

[28] T. Thomas and B. Burguera, "Is leptin the link between fat and bone mass?" Journal of Bone and Mineral Research, vol. 17, no. 9, pp. 1563-1569, 2002.

[29] J. A. Parnell and R. A. Reimer, "Prebiotic fibres dose-dependently increase satiety hormones and alter Bacteroidetes and Firmicutes in lean and obese JCR:LA cp rats," British Journal of Nutrition, vol. 107, no. 4, pp. 601-613, 2012.

[30] A. Matsunuma, T. Kawane, T. Maeda, S. Hamada, and N. Horiuchi, "Leptin corrects increased gene expression of renal 25-hydroxyvitamin D 3-1 $\alpha$-hydroxylase and -24-hydroxylase in leptin-deficient, ob/ob mice," Endocrinology, vol. 145, no. 3, pp. 1367-1375, 2004.

[31] R. D. Prisby, J. M. Swift, S. A. Bloomfield, H. A. Hogan, and M. D. Delp, "Altered bone mass, geometry and mechanical properties during the development and progression of type 2 diabetes in the Zucker diabetic fatty rat," Journal of Endocrinology, vol. 199, no. 3, pp. 379-388, 2008.

[32] T. Thomas, F. Gori, T. C. Spelsberg, S. Khosla, B. L. Riggs, and C. A. Conover, "Response of bipotential human marrow stromal cells to insulin-like growth factors: effect on binding protein production, proliferation, and commitment to osteoblasts and adipocytes," Endocrinology, vol. 140, no. 11, pp. 5036-5044, 1999.

[33] C. Hamann, C. Goettsch, J. Mettelsiefen et al., "Delayed bone regeneration and low bone mass in a rat model of insulinresistant type 2 diabetes mellitus is due to impaired osteoblast function," American Journal of Physiology, vol. 301, no. 6, pp. E1120-E1128, 2011.

[34] K. C. Li, R. F. Zernicke, R. J. Barnard, and A. F. Y. Li, "Effects of a high fat-sucrose diet on cortical bone morphology and biomechanics," Calcified Tissue International, vol. 47, no. 5, pp. 308-313, 1990.

[35] R. F. Zernicke, G. J. Salem, R. J. Barnard, and E. Schramm, "Long-term, high-fat-sucrose diet alters rat femoral neck and vertebral morphology, bone mineral content, and mechanical properties," Bone, vol. 16, no. 1, pp. 25-31, 1995.

[36] C. Lorincz, R. A. Reimer, S. K. Boyd, and R. F. Zernicke, "Highfat, sucrose diet impairs geometrical and mechanical properties of cortical bone in mice," British Journal of Nutrition, vol. 103, no. 9, pp. 1302-1308, 2010. 


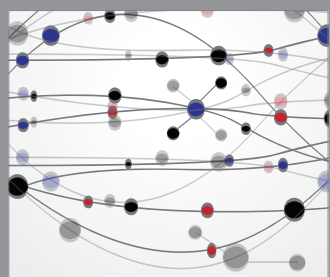

The Scientific World Journal
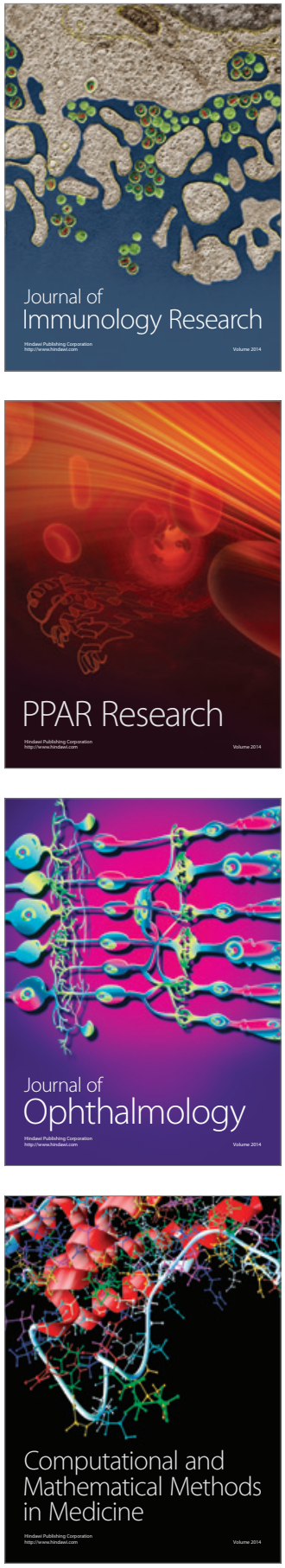

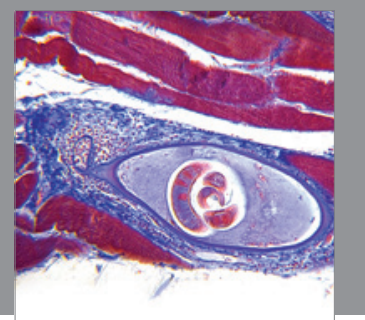

Gastroenterology

Research and Practice
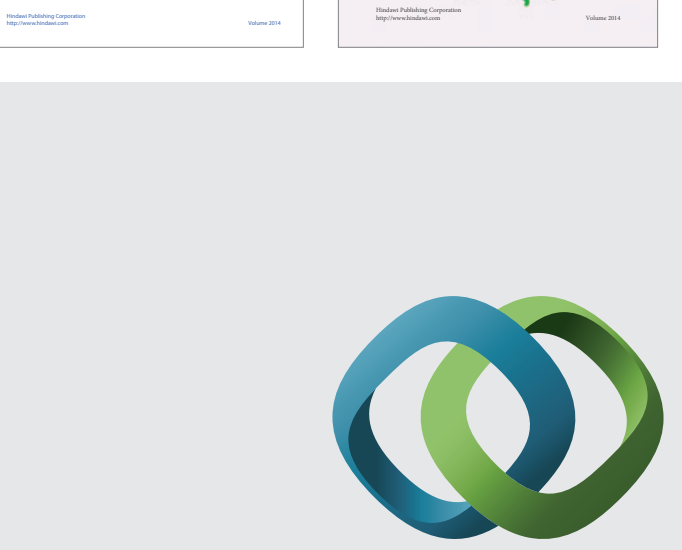

\section{Hindawi}

Submit your manuscripts at

http://www.hindawi.com
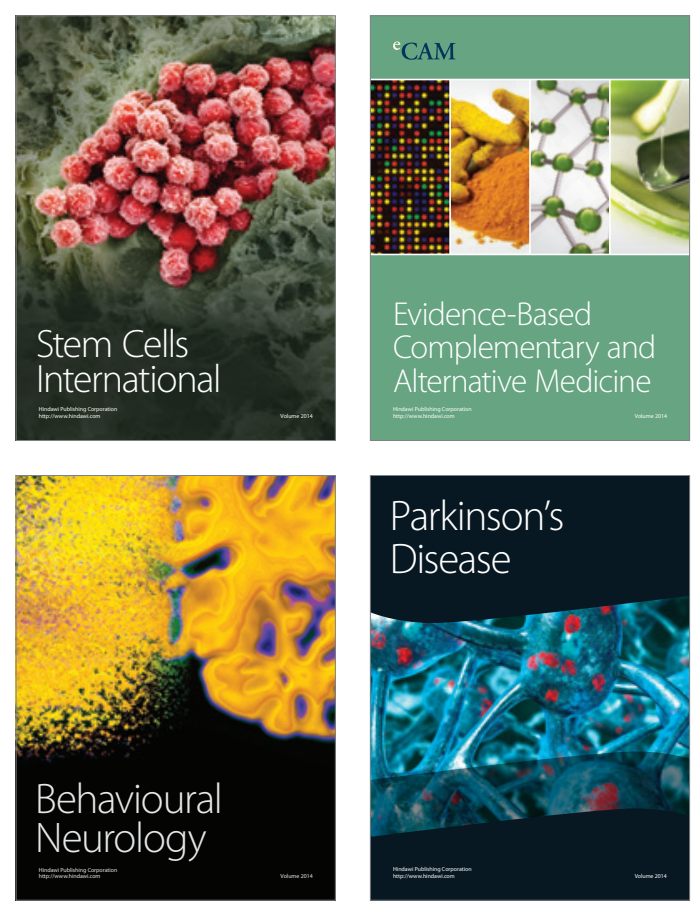

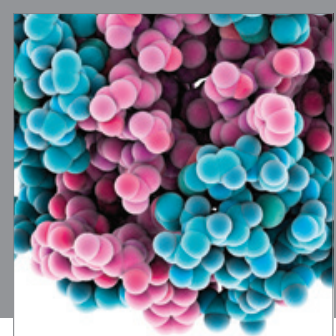

Journal of
Diabetes Research

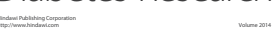

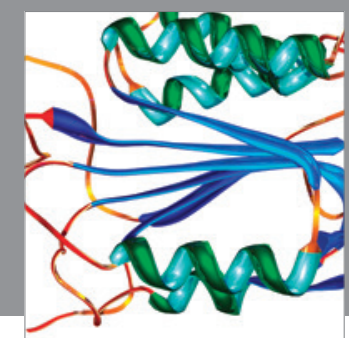

Disease Markers
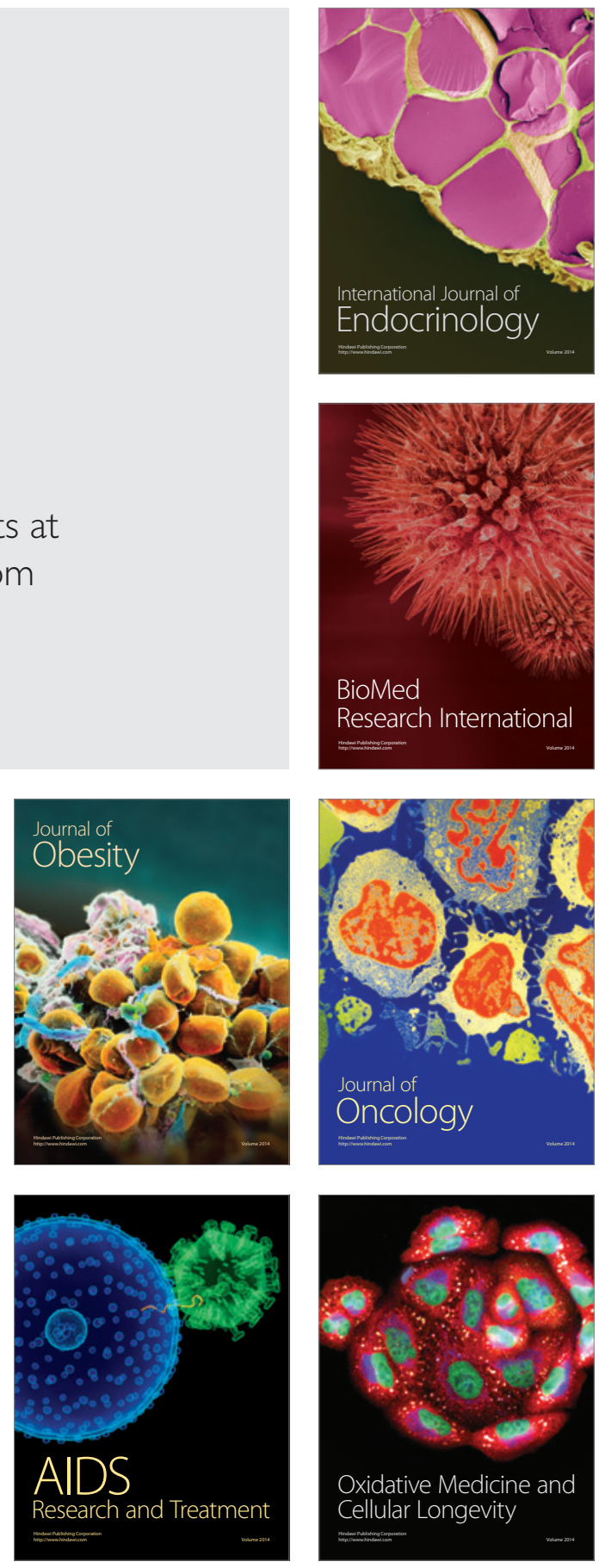